\title{
Optical coherence tomography findings in bipolar disorder: a preliminary receiver operating characteristic analysis on ganglion cell layer volume for diagnosis
}

\author{
SONER ALICI ${ }^{1}$ \\ https://orcid.org/0000-0002-7155-7530 \\ ÖZge SAHMELIKoĞLU ONUR ${ }^{1}$ \\ https://orcid.org/0000-0003-0447-4636 \\ ERCAN ÇAVUŞOĞLU² \\ https://orcid.org/0000-0002-5808-4839 \\ ISMAIL UMUT ONUR 2 \\ https://orcid.org/0000-0002-9028-2421 \\ Murat ERKIRAN 1 \\ https://orcid.org/0000-0003-3104-2265 \\ 1 Bakirkoy Prof. Dr. Mazhar Osman Ruh Sagligi ve Sinir Hastaliklari Egitim ve Arastirma Hastanesi, Istanbul, Turkey. \\ 2 Bakirkoy Dr. Sadi Konuk Egitim ve Arastirma Hastanesi - Ophthalmology, Istanbul, Turkey.
}

Received: 3/24/2019 - Accepted: 5/21/2019

DOl: 10.1590/0101-60830000000210

\begin{abstract}
Background: Optical coherence tomography (OCT) has been recently used to investigate neuropsychiatric disorders. Objective: The aim of this study was to compare the retinal nerve fiber layer thickness (RNFLT) and the ganglion cell layer (GCL) volume in patients with type 1 bipolar disorder (BPD1, diagnosed according to DSM 5) to the values in healthy controls. Methods: Eighty consecutive outpatients with a diagnosis of euthymic BPD1 and 80 healthy controls were enrolled in the study. Following assessment with the Sociodemographic Data Form, Structured Clinical Interview for DSM-IV (SCID-I), Hamilton Depression Scale and Young Mania Evaluation Scale, both groups underwent Optical coherence tomography (OCT). Results: The mean RNFL thickness and mean GCL volume were significantly lower in the BPD1 group than in the controls $(\mathrm{p}<0.05)$. The GCL global value had a significant and independent effect in distinguishing the BPD1 patients from the controls. A cut-off value of $101 \mathrm{~mm}^{3}$ for global GCL volume was proposed to distinguish BPD1 patients from controls with a sensitivity of $87.5 \%$. Discussion: Lower values of GCL volume and RNFLT in patients suffering from BPD1 suggest that neurodegeneration may occur during the course of BPD and that this degeneration can be characterized in particular by a thinning of the GCL volume.
\end{abstract}

Alici S et al. / Arch Clin Psychiatry. 2019;46(5):125-31

Keywords: Bipolar disorder, optic coherence tomography, neurodegeneration, retinal nerve fiber layer thickness, ganglion cell layer volume.

\section{Introduction}

Bipolar disorder (BPD), a chronic mental disorder with young age onset, causes severe disability ${ }^{1}$. Type 1 bipolar disorder (BPD1) shows a prevalence of $1 \%$ in the general population. The literature contains many theories regarding the etiology of $\mathrm{BPD}^{2}$, but a growing amount of evidence, especially from neuroimaging studies, now favors neurodegeneration as a cause ${ }^{3}$. Structural brain abnormalities, such as a progressive decline in grey matter volume in the hippocampus, fusiform gyrus, and cerebellum, together with temporal lobe ventricular enlargement in the first episode, are considered neurobiological markers for $\mathrm{BPD}^{4,5}$. Total brain gray matter deficit is suggested to be related to the duration of $\mathrm{BPD}^{6}$.

One consequence of neurodegenerative diseases (e.g., multiple sclerosis) is a reduction in retinal nerve fiber layer thickness (RNFLT), which can be detected by optical coherence tomography (OCT), a device that uses the reflection of infrared light off the back of the eye to quantify the thickness of retinal tissues, including the retinal nerve fiber layer (RNFL) and ganglion cell complex ${ }^{7}$. The RNFL involves axons of the ganglion cells, while the ganglion cell layer (GCL) involves the bodies of the ganglion cells 8 , and the reduction in the RNFLT can originate from axons and glia that have lost myelin?. Therefore, OCT is suggested to be a "window into the brain", serving as an objective tool to diagnose axonal damage ${ }^{10}$. Indeed, some researchers have found an association between the degeneration of retinal neurons and the severity of multiple sclerosis, Parkinson's disease, and Alzheimer's disease ${ }^{11-13}$.
The use of OCT has recently been suggested as a diagnostic tool for determining neuronal degeneration in psychiatric disorders ${ }^{14}$. In the first study reported in the literature, OCT measurements revealed a decreased RNFLT in patients with schizophrenia ${ }^{15}$. Lee et al. also found a relationship between abnormal OCT parameters and the duration of illness in patients with schizophrenia ${ }^{16}$. Dopamine plays a major role as a modulator in the retina, and retinal dopamine is decreased in patients with schizophrenia when compared to controls $^{17}$. However, Chu et al. did not find any difference in the RNFLT between patients with schizophrenia and those with schizoaffective disorder ${ }^{18}$.

Dopamine is one of the most important neurotransmitters in BPD, where it modulates symptoms such as psychotic episodes and cognitive dysfunction ${ }^{19}$. Kalenderoğlu et al. suggested that neurodegeneration occurring during the course of bipolar disorder might be demonstrated by decreases in the GCL in the early stages and may progress to involvement of other retinal layers, such as the RNFLT, at later stages ${ }^{20}$.

To the best of our knowledge, very few studies have investigated the relationship between neurodegeneration in BPD and OCT findings. The neurodegeneration that occurs throughout the course of BPD suggests that OCT findings, such as decreases in the RNFLT and GCL, may have therapeutic implications. In the current study, our aim was to examine the potential relationship between OCT findings and the clinical features of patients with BPD1 diagnosed by DSM 5 by comparing them with the findings in healthy controls. 


\section{Methods}

The study included 80 consecutive subjects, aged 18-65 years, who were recently diagnosed and/or had been followed up with a diagnosis of euthymic BPD 1 based on the DSM-5 criteria of a Young Mania Rating Scale (YMRS) score $<8$ and Hamilton Depression Inventory (HDI) Score $<8$. All subjects were recruited from Bakirkoy Training and Research Hospital Outpatient Clinic between September 2016 and April 2017, and diagnoses were obtained by means of the Structured Clinical Interview based on the DSM-IV axis I criteria ${ }^{21}$. A further 80 healthy subjects, matched to the patient group in terms of age and gender, were also included as a control group. The subjects in the control group had no psychiatric disorders according to DSM-IV, as determined by the Structured Clinical Interview non-patient edition ${ }^{22}$. Written informed consent was obtained from all subjects prior to enrollment. Individuals with cooperation problems or cognitive impairment as a result of mental retardation, neurological disease, or alcohol/drug use; those who had undergone electroconvulsive therapy in the last 6 months; and those with a history of psychosurgery or other brain surgery, head trauma, alcohol/drug addiction, psychotic symptoms, comorbidity, or any other psychiatric disease (for the patient group) or ophthalmologic disease (glaucoma, retinal disease, refraction disturbances) were excluded from the study. The study protocol was approved by the Ethics Committee of the Bakirkoy Training and Research Hospital (September 6th, 2016, protocol number 577).

The Socio-demographic Data Form, YMRS, and HDI questionnaires were administered to both the study and control groups. OCT assessments were performed by the Ophthalmology Department of the Bakırköy Dr. Sadi Konuk Research and Training Hospital. The RNFLT and GCL volume were measured and recorded with a spectral OCT instrument. Both groups were examined in the ophthalmology clinic, and visual acuity (best correct visual acuity, BCVA), intraocular pressure, slit lamp biomicroscopy, and fundus examinations were performed for all subjects. All patients and controls included in the study had normal ophthalmologic examination results.

\section{Instruments}

\section{Socio-demographic Data Form}

This form was prepared by the researchers to assess the participants' sociodemographic and clinical characteristics. The form was completed by the researchers while interviewing the control and patient groups.

\section{Young Mania Rating Scale (YMRS)}

The YMRS was developed by Young et al. and consists of 11 items, each measuring the severity of a symptom on a scale of $0-4{ }^{23}$. The items in the scale encompass the core symptoms of manic episodes. Assessment is based on an interview concerning the patient's state over the previous 48-hour period, as well as observations made during the interview. The validity and reliability studies for the Turkish version of the scale were conducted by Karadag et al. ${ }^{24}$.

\section{Hamilton Depression Inventory (HDI)}

We used the 17-item (HAM-D17) version endorsed by Hamilton et al. ${ }^{25}$. The HAM-D raters who participated in the present study had been trained as investigators in Bakırköy Research and Training Hospital trials. Turkish adaptation and reliability studies were undertaken by Akdemir et al. ${ }^{26}$.

\section{Structured Clinical Interview for DSM-IV (SCID-I)}

This is a diagnostic tool used to determine DSM-IV Axis I disorders, as assessed by a professional interviewer. Consisting of 6 modules, the instrument was developed by First et al. ${ }^{21,22}$. The validity and reliability of the Turkish version was confirmed by Ozkurkcugil under the name of the Structural Clinical Interview for DSM-IV Axis-I Disorders ${ }^{27}$.

\section{OCT measurement}

OCT images were taken and recorded from all the subjects in the patient and control groups using an Optovue RTVue Fourier domain OCT device (RTVue-100, 2007, version 3.0) in the Ophthalmology Polyclinic of Bakırkoy Dr Sadi Konuk Training and Research Hospital. RNFLT analysis and GCL scanning protocols were applied to map the optic nerve head of each eye (Figures 1 and 2). All tests were conducted by the same experienced OCT technician. The protocol consisted of $360^{\circ}$ scanning, taking the optic disc as the center, with a $3.45 \mathrm{~mm}$ diameter around the optic disc. The RNFLT was evaluated with the rapid RNFT test. The mean nerve fiber thickness value for all the eyes was automatically calculated in micrometers $(\mu \mathrm{m})$ with
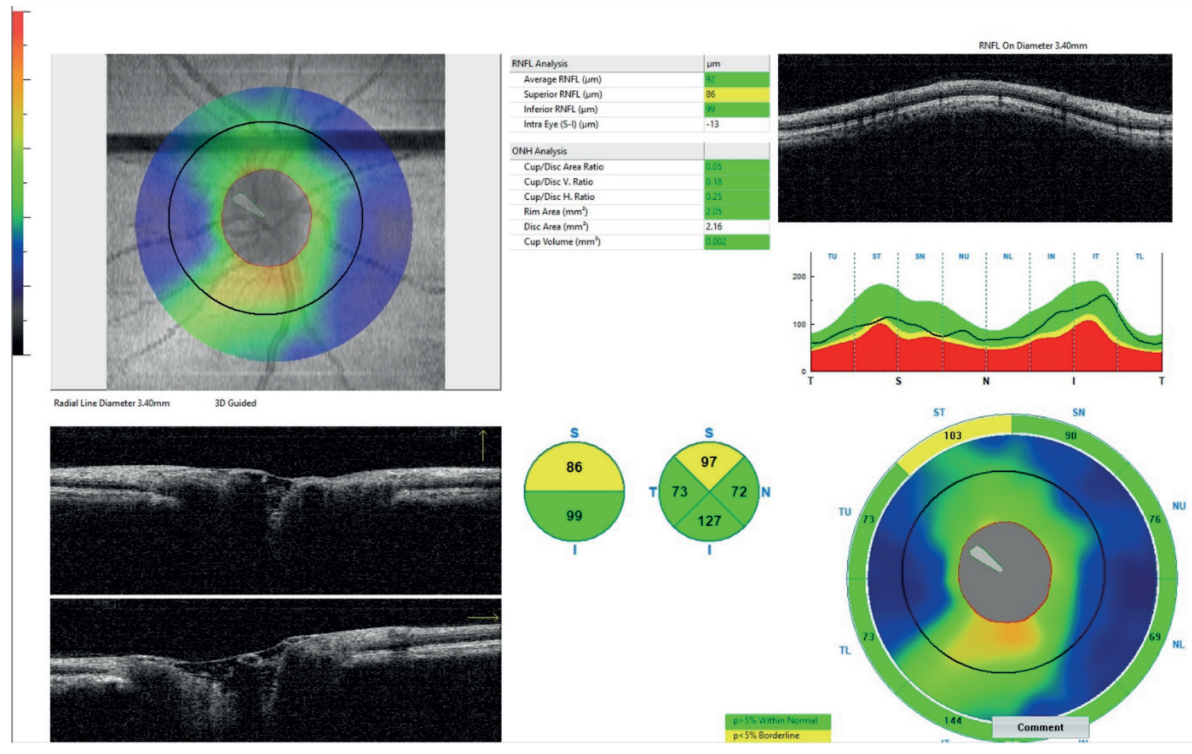

Figure 1. Evaluation of retinal nerve fiber layer thickness with OCT. S: superior; I: inferior; T: temporal; N: nasal. 
this method. The GCL scanning protocol was used to calculate the mean GCL value in $\mathrm{mm}^{3}$.

\section{Analyses}

All statistical analyses were performed using SPSS version 22.0 software (Microsoft Co., Chicago, IL, USA). The assumption of normality in the data was evaluated with the Kolmogorov-Smirnov test, and the data were presented as frequency (percentage) and mean \pm sd (standard deviation) values. The differences between the two groups were assessed using the Mann-Whitney $U$ test and the Chi-square test. Correlations were evaluated by Spearman correlation analysis. The levels of the effect and cut-off values were examined using ROC curve analysis. The effect level was examined by univariate and multivariate logistic regression analysis. The generalized estimating equations (GEE) method was used to compare the RNFLT and GCL volumes between the patient and control groups. GEE is an established method of analyzing paired biological data (e.g., OCT data from a pair of eyes) and enables the use of data from both eyes while protecting against the conflation of statistical significance that can result from the use of paired biological data from the same subject (i.e., pair of eyes) ${ }^{28}$. A value of $p<0.05$ was considered statistically significant.

\section{Results}

The BPD1 group and the healthy control group showed no statistically significant differences with respect to their sociodemographic variables of age and gender $(p>0.05)$. Statistically significant differences were observed with respect to their marital status, socio-economic level, education level, and occupation $(\mathrm{p}<$ 0.05). The education level, socioeconomic level, and occupation status values were lower in the BPD group than in the control group (Table 1).

Comparison of the RNFLT and GCL values revealed lower values in the BPD1 patients than in the control group for the RNFLT inferior and RNFLT global and the GCL inferior and GCL global $(\mathrm{p}<0.05)$. No statistically significant differences were determined between the groups in the RNFLT superior and GCL superior values $(\mathrm{p}>0.05)$ (Table 2).
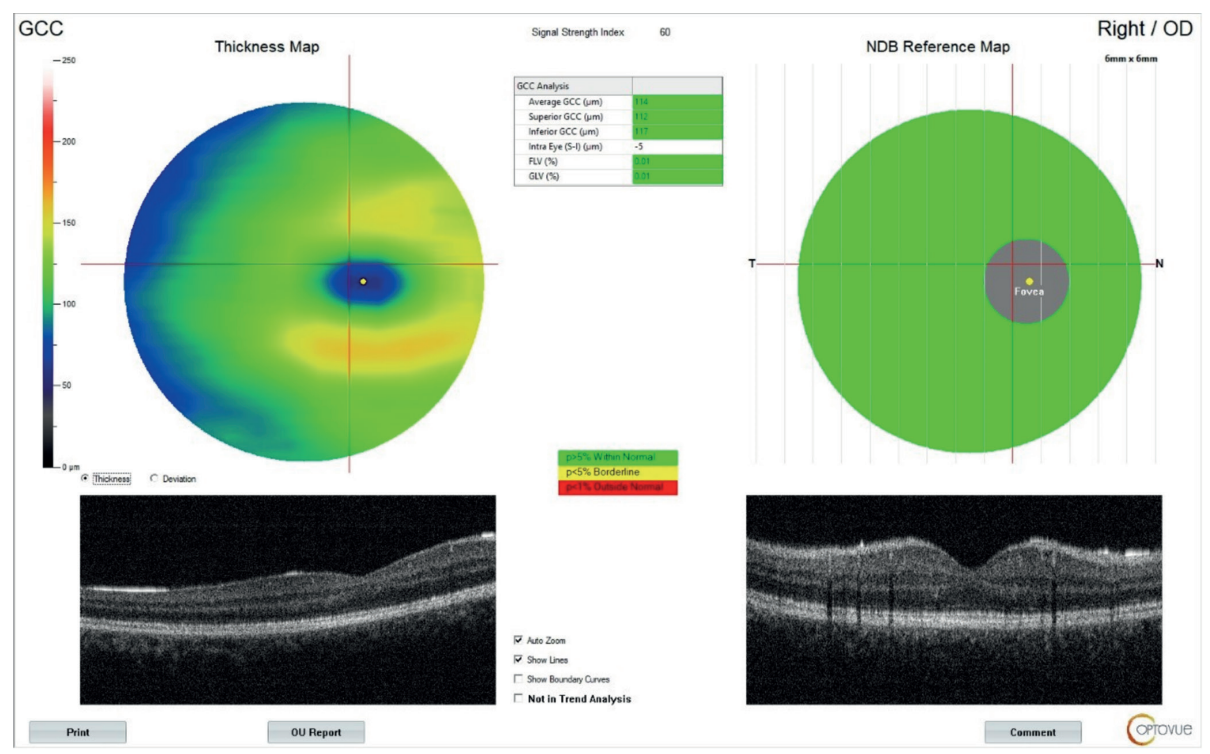

Figure 2. Evaluation of ganglion cell layer volume with OCT.

GCC: ganglion cell complex.

Table 1. Sociodemographic variables of groups

\begin{tabular}{|c|c|c|c|c|}
\hline & \multirow[t]{2}{*}{ Groups } & BPD1 n: 80 & Control n: 80 & \multirow[t]{2}{*}{$\mathrm{p}$} \\
\hline & & Mean $\pm \mathrm{sd} n / \%$ & Mean $\pm \mathrm{sd} \mathrm{n} / \%$ & \\
\hline Age & & $37.8 \pm 10.3$ & $36.9 \pm 8.9$ & 0,3671 \\
\hline \multirow[t]{2}{*}{ Sex } & Male & $37 / 46.2 \%$ & $41 / 51.2 \%$ & \multirow[t]{2}{*}{$0.527^{2}$} \\
\hline & Female & $43 / 53.8 \%$ & $39 / 48.8 \%$ & \\
\hline \multirow[t]{3}{*}{ Marital status } & Single & $30 / 37.5 \%$ & $23 / 28.8 \%$ & \multirow{3}{*}{$0.000^{2}$} \\
\hline & Married & $34 / 42.5 \%$ & $57 / 71.2 \%$ & \\
\hline & Widow/Divorced & $16 / 20.0 \%$ & $0 / 0 \%$ & \\
\hline \multirow[t]{5}{*}{ Education level } & None & $2 / 2.6 \%$ & $0 / 0 \%$ & \multirow{5}{*}{$0.000^{2}$} \\
\hline & Elementary & $23 / 28.8 \%$ & $19 / 23.8 \%$ & \\
\hline & Middle & $18 / 22.5 \%$ & $16 / 20.0 \%$ & \\
\hline & High & $32 / 40.0 \%$ & $15 / 18.8 \%$ & \\
\hline & University & $5 / 6.1 \%$ & $30 / 37.4 \%$ & \\
\hline \multirow[t]{2}{*}{ Occupation status } & Present & $50 / 62.5 \%$ & $77 / 96.3 \%$ & \multirow[t]{2}{*}{$0.000^{2}$} \\
\hline & Absent & $30 / 37.5 \%$ & $3 / 3.7 \%$ & \\
\hline
\end{tabular}

Mann-Whitney/2 Chi Square. sd: standard deviation; BPD1: bipolar disorder type 1; n: number of participiants.

The education level, socioeconomic level and occupation status values were statistically signifcant lower in the BPD group compared to the control group. 
No significant correlation was determined between the RNFLT global/GCL global and either the YMRS or HRS scores $(p=0.996 /$ $\mathrm{p}=0.528$ and $\mathrm{p}=0.137 / \mathrm{p}=0.601$ ), and no significant relationship was evident between RNFLT global/GCL global and age of onset ( $p=0.570$ and $p=0.445$ ). No significant relationship was found between the RNFLT global/GCL global and the duration of illness ( $p=0.559$ and $p=0.941)$ or between RNFLT global/GCL global and the number of hospitalizations $(\mathrm{p}=0.301$ and $\mathrm{p}=0.925)$ (Table 3 ). No significant correlation was determined between the number of any kind of episodes (manic or depressive) on presentation and the RNFLT global/GCL global (Table 3).

The univariate model revealed statistically significant effects for the RNFLT global, RNFLT superior, RNFLT inferior, GCL global,
GCL superior, and GCL inferior values $(\mathrm{p}<0.05)$ (Table 4$)$. The multivariate model revealed a significant and independent effect for the GCL global value (Table 4).

The GCL value had a significant effect in the differentiation of the patient and control groups (AUC 0.700; 0.620-0.781). The GCL cut-off value of $101 \mathrm{~mm}^{3}$ was significant for the differentiation of the patient and control groups (AUC 0.688; 0.604-0.771), with a sensitivity of $87.5 \%$, a specificity of $47.5 \%$, a positive predictive value (PPV) of 52.5\%, and a negative predictive value (NPV) of $79.2 \%$ (Figure 3 ).

A comparison of the RNFLT and GCL values of patients taking valproic acid and lithium revealed lower values in the patients taking valproic acid than in patients taking lithium with respect to the

Table 2. Comparison of RNFLT and GCL subscores of groups

\begin{tabular}{|l|c|c|c|}
\hline & BPD1 n: 80 & Control n: 80 & P0 \\
\cline { 2 - 3 } & Mean \pm sd & Mean \pm sd & \\
\hline RNFLT superior & $105.4829 \pm 16.2090 \mu \mathrm{m}$ & $109.3553 \pm 11.0719 \mu \mathrm{m}$ & 0.2091 \\
\hline RNFLT inferior & $101.2387 \pm 10.2108 \mu \mathrm{m}$ & $107.0535 \pm 9.5737 \mu \mathrm{m}$ & $0.016^{1}$ \\
\hline RNFLT global & $103.3808 \pm 11.6999 \mu \mathrm{m}$ & $108.1990 \pm 9.0703 \mu \mathrm{m}$ & $0.028^{1}$ \\
\hline GCL superior & $93.2546 \pm 8.5765 \mathrm{~mm}^{3}$ & $95.6779 \pm 5.3231 \mathrm{~mm}^{3}$ & $0.073^{1}$ \\
\hline GCL inferior & $93.1591 \pm 8.4444 \mathrm{~mm}^{3}$ & $96.9529 \pm 4.2096 \mathrm{~mm}^{3}$ & $0.028^{1}$ \\
\hline GCL global & $93.1128 \pm 8.5045 \mathrm{~mm}^{3}$ & $96.3100 \pm 4.6009 \mathrm{~mm}^{3}$ & $0.041^{1}$ \\
\hline
\end{tabular}

1 Mann-Whitney. RNFLT: retinal nerve fiber layer thickness; GCL: ganglion cell layer; $\mu \mathrm{m}$ : micrometer; $\mathrm{mm}^{3}$ : millimeter cube; Sd: standard deviation $\mathrm{n}$ : number of participiants. RNFLT inferior and RNFLT global, GCL inferior and GCL global values were significantly statistically lower in BPD1 group than controls.

Table 3. Variables in the case group and their relations with RNFLT and GCL

\begin{tabular}{|c|c|c|c|c|c|c|}
\hline & Age of onset (years) & YMRS & $\mathrm{HDI}$ & Number of hospitalization & Duration of illness \\
\hline & & Mean $\pm s d$ & Mean \pm sd & Mean $\pm s d$ & Mean $\pm s d$ & Mean \pm sd \\
\hline & & $24.512 \pm 7.75$ & $4.20 \pm 1.39$ & $4.80 \pm 1.27$ & $2.73 \pm 2.47$ & $13.18 \pm 9.17$ \\
\hline \multirow[t]{2}{*}{ RNFLT global } & $r$ & -0.066 & -0.005 & -0.171 & -0.246 & -0.068 \\
\hline & $p$ & 0.570 & 0.996 & 0.137 & 0.301 & 0.559 \\
\hline \multirow[t]{2}{*}{ GCL global } & $r$ & -0.087 & -0.072 & -0.059 & -0.011 & -0.008 \\
\hline & $p$ & 0.445 & 0.528 & 0.601 & 0.925 & 0.941 \\
\hline & & $\begin{array}{c}\text { Number of depressive } \\
\text { episodes }\end{array}$ & $\begin{array}{l}\text { Number of manic } \\
\text { episodes }\end{array}$ & \multicolumn{2}{|c|}{$\begin{array}{l}\text { Depressive episode } \\
\text { number } / \mathrm{n}(\%)\end{array}$} & $\begin{array}{c}\text { Manic episode } \\
\text { number/n }(\%)\end{array}$ \\
\hline \multirow[t]{2}{*}{ RNFLT global } & $r$ & -0.087 & -0.140 & \multirow{4}{*}{\multicolumn{2}{|c|}{$\begin{array}{c}0 \rightarrow(20 \%) \\
1 \rightarrow 27(16.9 \%) \\
2 \rightarrow 16(10 \%) \\
3 \rightarrow 8(5 \%) \\
4 \rightarrow 7(4.4 \%) \\
7 \rightarrow 1(0.6 \%) \\
10 \rightarrow 1(0.6 \%)\end{array}$}} & $1 \rightarrow 36(45 \%)$ \\
\hline & $p$ & 0.453 & 0.225 & & & $2 \rightarrow 11(58.8 \%)$ \\
\hline \multirow[t]{2}{*}{ GCL global } & $r$ & -0.031 & $-0,53$ & & & $3 \rightarrow 17(10.6 \%)$ \\
\hline & $p$ & 0.788 & 0.641 & & & $\begin{array}{l}4 \rightarrow 5(3.1 \%) \\
5 \rightarrow 4(2.5 \%) \\
6 \rightarrow 5(3.1 \%) \\
7 \rightarrow 1(0.6 \%) \\
9 \rightarrow 1(0.6 \%)\end{array}$ \\
\hline
\end{tabular}

Spearman correlation. RNFLT: retinal nerve fiber layer thickness; GCL: ganglion cell layer; n: number of participiants; YMRS: Young Mania Rating Scale; HDI: Hamilton Depression Inventory; sd: standard deviation.

No significant correlation was determined between RNFLT global/GCL global anda age of onset, YMRS, HDIscores, number of hospitalization, duration of illness and number of episodes.

Table 4. Regression Analysis of RNFLT and GCL values in the differentiation of BPD patients from healthy control subjects

\begin{tabular}{|c|c|c|c|c|c|c|}
\hline & \multicolumn{3}{|c|}{ Univariate Model } & \multicolumn{2}{c|}{ Multivariate Model } \\
\cline { 2 - 7 } & OR & $\% 95$ & $p$ & OR & \\
\hline RNFLT & & & & & \\
\hline Global & 0.942 & $0.913-0.974$ & 0.000 & & \\
\hline Superior & 0.964 & $0.942-0.985$ & 0.001 & & \\
\hline Inferior & 0.943 & $0.916-0.971$ & 0.000 & & \\
\hline GCL & & & & & \\
\hline Global & 0.937 & $0.896-0.980$ & 0.004 & 0.937 & $0.896-0.980$ & \\
\hline Superior & 0.943 & $0.903-0.984$ & 0.007 & & & \\
\hline Inferior & 0.937 & $0.896-0.980$ & 0.004 & & & \\
\hline
\end{tabular}

Logistic Regression Analysis. OR: odds ratio; RNFLT: retinal nerve fiber layer thickness; GCL: ganglion cell layer.

GCL global value was determined to have a significant and independent effect to distunguish BPD1 patients and healthy controls $(p<0.05)$. 
RNFLT inferior, RNFLT global, GCL inferior, and GCL global values $(p<0.05)$. No statistically significant difference was determined for the comparison of the RNFLT superior and GCL superior values $(\mathrm{p}>0.05)$ (Table 5).

\section{Discussion}

The results of this study demonstrated that the RNFLT and GCL were thinner in patients with BPD1 than in control subjects. In addition, the GCL global volume showed significant and independent efficacy in differentiating the BPD 1 group from the control group. These results differ in some respects from the previous literature regarding the association between the clinical features of BPD1 and the RNFLT and GCL volume.

Mehraban et al. revealed that the superior, inferior, and total RNFLT were thinner in patients with BPD1 than in a control group. In the current study, statistically significant decreases were also observed in the thickness of the superior and global RNFL in the BPD1 group ${ }^{29}$. Kalenderoğlu et al. found decreases in all parts of the RNFLT, although only the difference in the global RNFLT was statistically significant ${ }^{20}$. In that study, the decrease was reported as being much more prominent in the GCL volume than in the RNFLT. The results of the current study also demonstrated that the GCL global volume had a significant and independent efficacy for differentiating the BPD1 group from the control group. A cut-off value of $101 \mathrm{~mm}^{3}$ was calculated for the global GCL to distinguish BPD1 patients from healthy control subjects and gave a sensitivity of $87.5 \%$ and a

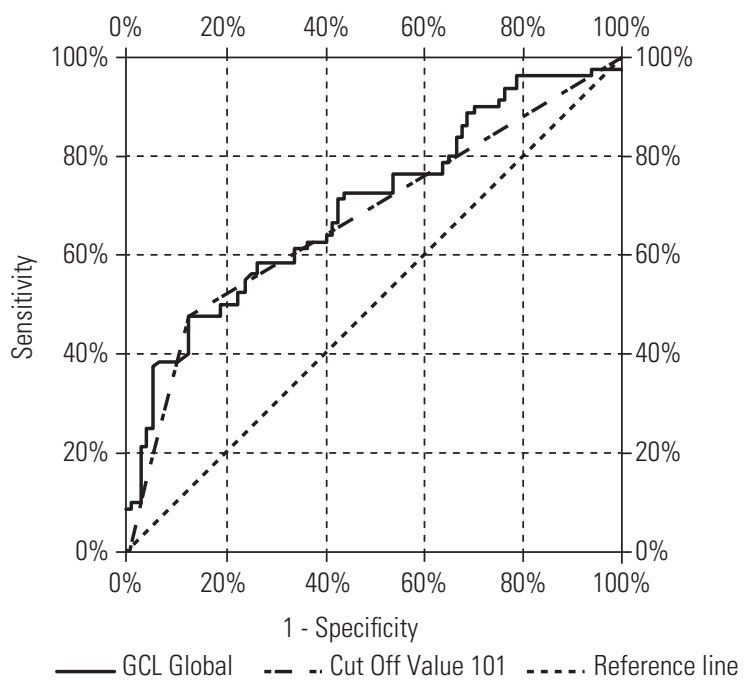

Figure 3. GCL cut-off values in the differentiation of BPD1 patients from healthy controls.

GCL: ganglion cell layer.

A cut-off value of $101 \mathrm{~mm}^{3}$ for global GCL volume was also proposed to distinguish BPD1 patients from healthy controls with the sensitivity of $87.5 \%$. specificity of $47.5 \%$. Although this specificity is low, the current study results support the idea that neurodegeneration in BPD1 starts in the GCL, which forms the neuronal cell bodies, and then gradually progresses to axonal degeneration. The most compelling aspect of the current study results is that neuronal degeneration in BPD1 can be characterized by the thinning of the GCL and that OCT findings may be used as high-sensitivity markers in the follow-up of BPD1 patients.

Despite the evidence showing the correlation of gray matter loss to the number of mood disorder episodes as a factor of severity ${ }^{4}$, the same pattern could not be found in the current study for the number of manic or depressive episodes, or both together, or for the age of onset, in agreement with the study by Mehraban et al. ${ }^{29}$. This might be explained by the fact that $36 \%$ of our cases had only experienced one mania attack and that RNFLT loss may be more strongly associated with manic attacks than with depression. Larger patient recruitment might be necessary to obtain sufficient numbers for subgroup analysis, since the severity of the disorder is directly related to the severity of neural loss ${ }^{30}$. In a study comparing schizophrenia patients with a recent illness episode (RIE) and schizophrenia patients without a RIE, Ascaso et al. suggested that neuroinflammation occurs during illness episodes and this masks the decrease in RNFLT in schizophrenia patients during the acute episode due to the increase in retina thickness ${ }^{31}$. Patient comparisons according to RIEs may be needed to understand the effect of neuroinflammation on the RNFLT. Furthermore, structural changes, such as gray or white matter loss, occur at the onset of BPD ${ }^{32}$, revealing a neurodevelopmental basis for neural deficits ${ }^{32,33}$. Similarly, a dual process model of gray matter loss could explain how BPD might emerge with neurodevelopmental loss and continue with progressive neurodegenerative loss ${ }^{34,35}$.

Kalenderoğlu et al. revealed a statistically significant relationship between the duration of disease and RNFLT loss $^{20}$, as did Mehraban et al. ${ }^{29}$. Another study also showed that the duration of schizophrenia was correlated to RNFLT thinning ${ }^{16}$. However, in the current study, no significant relationship was evident between the duration of the disease and RNFLT. The variation in these findings could be attributed to the higher mean age of the current study BPD1 group compared to the study group investigated by Mehraban et al.29. Although our groups were age matched, age may be a confounding variable because of the relationship between age and thinning RNFLT, as evidence shows that patients with BPD1 undergo more progressive brain-aging changes, such as loss of gray matter intensity, when compared with the normal population ${ }^{36}$. Moreover, unlike the study of Mehraban et al., patients with psychotic symptoms at the time of scan were excluded from the present study due to the probable effect of psychosis on gray matter loss and a potential independent reduction in the RNFLT29,36. Furthermore, the sample size was larger in the current study than in the previous studies 20,29 .

Previous research has indicated that the volumes of the hippocampus, amygdala, anterior cingulate, and subgenual cingulate are larger in patients taking lithium than in patients not taking lithium $^{37}$. Pardoe et al. also demonstrated that valproic acid use was related to a reduced brain volume in epilepsy patients ${ }^{38}$. In another study, valproic acid was claimed to have neuroprotective and neurotrophic effects and to decrease gray matter loss in BPD1

Table 5. Comparison of the RNFLT and GCL values of patients taking lithium and valproic acid

\begin{tabular}{|l|c|c|c|}
\hline \multirow{2}{*}{} & Lithium $(\mathrm{n}=36)$ & Valproic acid $(\mathrm{n}=30)$ & \multirow{2}{*}{$p$} \\
\cline { 2 - 3 } & mean $\pm \mathrm{sd}$ & mean \pm sd & \\
\hline RNFLT superior & $109.3553 \pm 11.0719 \mu \mathrm{m}$ & $105.4829 \pm 16.2090 \mu \mathrm{m}$ & 0.209 \\
\hline RNFLT inferior & $107.0535 \pm 9.5737 \mu \mathrm{m}$ & $101.2387 \pm 10.2108 \mu \mathrm{m}$ & 0.016 \\
\hline RNFLT global & $108.1990 \pm 9.0703 \mu \mathrm{m}$ & $103.3808 \pm 11.6999 \mu \mathrm{m}$ & 0.028 \\
\hline GCL superior & $95.6779 \pm 5.3231 \mathrm{~mm}^{3}$ & $93.2546 \pm 8.5765 \mathrm{~mm}^{3}$ & 0.073 \\
\hline GCL inferior & $96.9529 \pm 4.2096 \mathrm{~mm}^{3}$ & $93.1591 \pm 8.4444 \mathrm{~mm}^{3}$ & 0.028 \\
\hline
\end{tabular}

Mann-Whitney test. RNFLT: retinal nerve fiber layer thickness; GCL: ganglion cell layer; Sd: standard deviation; n: number of participiants; $\mu$ m: micrometer; mm³: millimeter cube. BPD1 patients taking valproic acid were determined with lower values than patients taking lithium in respect of RNFLT inferior, RNFLT global, GCL inferior and GCL global ( $p<0.05)$. 
patients $^{3}$. In the current study, the BPD1 patients using lithium had significantly higher global RNFLT and global GCL volume when compared to the patients using valproic acid. To the best of our knowledge, this is the first study to explore differences in OCT parameters between patients using lithium and valproic acid. The striking results reported here may serve to enlighten our understanding of BPD1 treatment in regards to the neuroprotective effect of lithium, as well as the efficacy of using OCT to detect valproic acid-induced decreases in gray matter. However, many other potential confounders may have affected the present results, so further studies are needed to confirm these possibilities.

One limitation of the present study is that we recruited only euthymic patients under pharmacotherapy. Another limitation is that we did not compare the BPD1 and control groups in terms of smoking, nor did we exclude controls "being at risk" (i.e., those with a first-degree relative diagnosed with a psychiatric disorder). The patients were primarily at an early stage of progression, so this too could affect the ability to observe a relationship between the number of episodes and the biological measures.

Overall, our study sample results suggest that neurodegeneration may manifest itself particularly as changes in the GCL volume and RNFLT and that lithium may be more neuroprotective than valproic acid. These findings can be considered of importance as they have implications for the neurobiology of BPD1, its treatment considerations, and the course of the disease. Further studies using OCT are needed to compare first-episode BPD1 patients with multiple-episode BPD1 patients to obtain a better understanding of the effect of manic and depressive episodes.

\section{Conflict of interest}

This research did not receive any specific grant from funding agencies in the public, commercial, or not-for-profit sectors. The authors are responsible for the content and writing of the paper.

\section{Funding}

None.

\section{Acknowledgment}

There are no acknowledgements for this manuscript submission.

\section{References}

1. Begley CE, Annegers JF, Swann AC, Lewis C, Coan S, Schnapp WB, et al. The lifetime cost of bipolar disorder in the US: an estimate for new cases in 1998. Pharmacoeconomics. 2001;19(5 Pt 1):483-95.2.

2. Merikangas KR, Akiskal HS, Angst J, Greenberg PE, Hirschfeld RM, Petukhova M, et al. Lifetime and 12-month prevalence of bipolar spectrum disorder in the National Comorbidity Survey replication. Arch Gen Psychiatry. 2007;64(5):543-52.

3. Kempton MJ, Geddes JR, Ettinger U, Williams SC, Grasby PM. Metaanalysis, database, and meta-regression of 98 structural imaging studies in bipolar disorder. Arch Gen Psychiatry. 2008;65(9):1017-32.

4. Moorhead TW, McKirdy J, Sussmann JE, Hall J, Lawrie SM, Johnstone EC, et al. Progressive gray matter loss in patients with bipolar disorder. Biol Psychiatry. 2007;62(8):894-900.

5. Vita A, De Peri L, Sacchetti E. Gray matter, white matter, brain, and intracranial volumes in first-episode bipolar disorder: a meta-analysis of magnetic resonance imaging studies. Bipolar Disord. 2009;11(8):807-14.

6. Frey BN, Zunta-Soares GB, Caetano SC, Nicoletti MA, Hatch JP, Brambilla P, et al. Illness duration and total brain gray matter in bipolar disorder: evidence for neurodegeneration? Eur Neuropsychopharmacol. 2008;18(10):717-22.

7. Fujimoto JG. Optical coherence tomography for ultrahigh resolution in vivo imaging. Nat Biotechnol. 2003;21(11):1361-7.

8. Parver LM. Temperature modulating action of choroidal blood flow. Eye (Lond). 1991;5(Pt 2):181-5.
9. Galetta KM, Calabresi PA, Frohman EM, Balcer LJ. Optical coherence tomography (OCT): imaging the visual pathway as a model for neurodegeneration. Neurotherapeutics. 2011;8(1):117-32.

10. Schönfeldt-Lecuona C, Kregel T, Schmidt A, Pinkhardt EH, Lauda F, Kassubek J, et al. From Imaging the brain to imaging the retina: optical coherence tomography (OCT) in Schizophrenia. Schizophr Bull. 2016;42(1):9-14.

11. Petzold A, de Boer JF, Schippling S, Vermersch P, Kardon R, Green A, et al. Optical coherence tomography in multiple sclerosis: a systematic review and meta-analysis. Lancet Neurol. 2010;9(9):921-32.

12. Inzelberg R, Ramirez JA, Nisipeanu P, Ophir A. Retinal nerve fiber layer thinning in Parkinson disease. Vision Res. 2004;44(24):2793-7.

13. Lu Y, Li Z, Zhang X, Ming B, Jia J, Wang R, et al. Retinal nerve fiber layer structure abnormalities in early Alzheimer's disease: evidence in optical coherence tomography. Neurosci Lett. 2010;480(1):69-72.

14. Karadag AS, Kalenderoglu A, Orum MH. Optical coherence tomography findings in conversion disorder: are there any differences in the etiopathogenesis of subtypes? Arch Clin Psychiatry (São Paulo). 2018;45(6):154-60.

15. Ascaso FJ, Cabezón L, Quintanilla MÁ, Gutiérrez Galve L, López-Antón $\mathrm{R}$, Cristóbal JA, et al. Retinal nerve fiber layer thickness measured by optical coherence tomography in patients with schizophrenia: a short report. Eur J Psychiatry. 2010;24(4):227-35.

16. Lee WW, Tajunisah I, Sharmilla K, Peyman M, Subrayan V. Retinal nerve fiber layer structure abnormalities in schizophrenia and its relationship to disease state: evidence from optical coherence tomography. Invest Ophthalmol Vis Sci. 2013;54(12):7785-92.

17. Djamgoz MB, Hankins MW, Hirano J, Archer SN. Neurobiology of retinal dopamine in relation to degenerative states of the tissue. Vision Res. 1997;37(24):3509-29.

18. Chu EM, Kolappan M, Barnes TR, Joyce EM, Ron MA. A window into the brain: an in vivo study of the retina in schizophrenia using optical coherence tomography. Psychiatry Res. 2012;203(1):89-94.

19. Harnois C, Di Paolo T. Decreased dopamine in the retinas of patients with Parkinson's disease. Invest Ophthalmol Vis Sci. 1990;31(11):2473-5.

20. Kalenderoglu A, Sevgi-Karadag A, Celik M, Egilmez OB, Han-Almis $\mathrm{B}$, Ozen ME. Can the retinal ganglion cell layer (GCL) volume be a new marker to detect neurodegeneration in bipolar disorder? Compr Psychiatry. 2016;67:66-72.

21. First MB, Spitzer RL, Gibbon M, Williams JB. Structured clinical interview for DSM-IV-TR axis I disorders, research version, patient edition (SCID-I/P). New York: Biometrics Research; 2002.

22. First MB, Spitzer RL, Gibbon M, Williams JB. Structured clinical interview for DSM-IV-TR axis I disorders, research version, Non-patient edition (SCID-I/P). New York: Biometrics Research; 2002.

23. Young RC, Biggs JT, Ziegler VE, Meyer DA. A rating scale for mania: reliability, validity and sensitivity. Br J Psychiatry. 1978;133:429-35.

24. Karadağ F, Oral T, Yalçin FA, Erten E. [Reliability and validity of Turkish translation of Young mania rating scale]. Turk Psikiyatri Derg. 2002;13(2):107-14.

25. Hamilton M. A rating scale for depression. J Neurol Neurosurg Psychiatry. 1960;23:56-62.

26. Akdemir A, Orsel S, Dag I, Turkcapar H, Iscan N, Ozbay H. Validity, reliability and clinical use of Hamilton depression rating scale. Psikiyatri Psikoloji Psikofarmakoloji Dergisi. 1996;4:251-9.

27. Ozkürkçügil A, Aydemir Ö, Yıldız MK, Danacı E, Köroğlu E. DSMIV Eksen I bozuklukları için yapılandırılmış klinik görüşmenin Türkçe’ye uyarlanması ve güvenilirlik çalışması. İlaç ve Tedavi Dergisi. 1999;12(4):233-6.

28. Hanley JA, Negassa A, Edwardes MD, Forrester JE. Statistical analysis of correlated data using generalized estimating equations: an orientation. Am J Epidemiol. 2003;157(4):364-75.

29. Mehraban A, Samimi SM, Entezari M, Seifi MH, Nazari M, Yaseri M. Peripapillary retinal nerve fiber layer thickness in bipolar disorder. Graefes Arch Clin Exp Ophthalmol. 2016;254(2):365-71.

30. Strakowski SM, DelBello MP, Zimmerman ME, Getz GE, Mills NP, Ret $\mathrm{J}$, et al. Ventricular and periventricular structural volumes in first- versus multiple-episode bipolar disorder. Am J Psychiatry. 2002;159(11):1841-7.

31. Ascaso FJ, Rodriguez-Jimenez R, Cabezón L, López-Antón R, Santabárbara J, De la Cámara C, et al. Retinal nerve fiber layer and macular thickness in patients with schizophrenia: influence of recent illness episodes. Psychiatry Res. 2015;229(1-2):230-6. 
32. Adler CM, Adams J, DelBello MP, Holland SK, Schmithorst V, Levine A, et al. Evidence of white matter pathology in bipolar disorder adolescents experiencing their first episode of mania: a diffusion tensor imaging study. Am J Psychiatry. 2006;163(2):322-4.

33. Strakowski SM, Wilson DR, Tohen M, Woods BT, Douglass AW, Stoll AL. Structural brain abnormalities in first-episode mania. Biol Psychiatry. 1993;33(8-9):602-9.

34. Farrow TF, Whitford TJ, Williams LM, Gomes L, Harris AW. Diagnosisrelated regional gray matter loss over two years in first episode schizophrenia and bipolar disorder. Biol Psychiatry. 2005;58(9):713-23.

35. Yatham LN, Lyoo IK, Liddle P, Renshaw PF, Wan D, Lam RW, et al. A magnetic resonance imaging study of mood stabilizer- and neurolepticnaïve first-episode mania. Bipolar Disord. 2007;9(7):693-7.
36. Yatham LN, Kapczinski F, Andreazza AC, Trevor Young L, Lam RW, Kauer-Santanna M. Accelerated age-related decrease in brain-derived neurotrophic factor levels in bipolar disorder. Int J Neuropsychopharmacol. 2009;12(1):137-9.

37. Chiu CT, Wang Z, Hunsberger JG, Chuang DM. Therapeutic potential of mood stabilizers lithium and valproic acid: beyond bipolar disorder. Pharmacol Rev. 2013;65(1):105-42.

38. Pardoe HR, Berg AT, Jackson GD. Sodium valproate use is associated with reduced parietal lobe thickness and brain volume. Neurology. 2013;80(20):1895-900. 